\title{
Life goal attainment in the adaptation process after acquired brain injury: the influence of self-efficacy and of flexibility and tenacity in goal pursuit
}

Citation for published version (APA):

Brands, I., Stapert, S., Köhler, S., Wade, D., \& van Heugten, C. (2015). Life goal attainment in the adaptation process after acquired brain injury: the influence of self-efficacy and of flexibility and tenacity in goal pursuit. Clinical Rehabilitation, 29(6), 611-622. https://doi.org/10.1177/0269215514549484

Document status and date:

Published: 01/06/2015

DOI:

10.1177/0269215514549484

Document Version:

Publisher's PDF, also known as Version of record

Document license:

Taverne

Please check the document version of this publication:

- A submitted manuscript is the version of the article upon submission and before peer-review. There can be important differences between the submitted version and the official published version of record.

People interested in the research are advised to contact the author for the final version of the publication, or visit the DOI to the publisher's website.

- The final author version and the galley proof are versions of the publication after peer review.

- The final published version features the final layout of the paper including the volume, issue and page numbers.

Link to publication

\footnotetext{
General rights rights.

- You may freely distribute the URL identifying the publication in the public portal. please follow below link for the End User Agreement:

www.umlib.nl/taverne-license

Take down policy

If you believe that this document breaches copyright please contact us at:

repository@maastrichtuniversity.nl

providing details and we will investigate your claim.
}

Copyright and moral rights for the publications made accessible in the public portal are retained by the authors and/or other copyright owners and it is a condition of accessing publications that users recognise and abide by the legal requirements associated with these

- Users may download and print one copy of any publication from the public portal for the purpose of private study or research.

- You may not further distribute the material or use it for any profit-making activity or commercial gain

If the publication is distributed under the terms of Article $25 \mathrm{fa}$ of the Dutch Copyright Act, indicated by the "Taverne" license above, 


\title{
Life goal attainment in the adaptation process after acquired brain injury: the influence of self-efficacy and of flexibility and tenacity in goal pursuit
}

Clinical Rehabilitation 2015, Vol. 29(6) 6II-622 (C) The Author(s) 2014 Reprints and permissions: sagepub.co.uk/journalsPermissions.nav DOI: $10.1177 / 0269215514549484$ cre.sagepub.com

@SAGE

\section{Ingrid Brands', Sven Stapert ${ }^{2}$, Sebastian Köhler ${ }^{3}$, Derick Wade ${ }^{4,5}$ and Caroline van Heugten ${ }^{2,3}$}

\begin{abstract} equation modelling were used.

'Department of Neurorehabilitation, Libra Rehabilitation Medicine and Audiology, Eindhoven, The Netherlands 2Department of Neuropsychology and Psychopharmacology, Faculty of Psychology and Neuroscience, Maastricht University, Maastricht, The Netherlands

${ }^{3}$ School for Mental Health and Neuroscience, Alzheimer Centre Limburg, Faculty of Health, Medicine and Life Sciences, Maastricht University, Maastricht, The Netherlands
\end{abstract}

Objective: To investigate attainment of important life goals and to examine whether self-efficacy, tenacity in goal pursuit and flexibility in goal adjustment contribute to adaptation by affecting levels of emotional distress and quality of life in patients with newly acquired brain injury.

Methods: Data were collected from a prospective clinical cohort study of I48 patients assessed after discharge home (mean time since injury $=15$ weeks) and one year later. At follow-up, attainment of life goals (set at baseline) and satisfaction with attainment was scored (I0-point scale) and patients were asked how they adjusted unattained goals. Emotional distress was measured with the Hospital Anxiety and Depression Scale (HADS), quality of life with the Life Satisfaction Questionnaire (LiSat-9), selfefficacy with the TBI Self-efficacy Questionnaire (SEsx) and tenacity and flexibility with the Assimilative/ Accommodative Coping Questionnaire (AACQ). Random effects regression analyses and structural

Results: In total, only $13 \%$ of initial life goals were achieved in one year. Patients who maintained efforts to reach their original goals had higher average levels of tenacity, but did not differ in level of selfefficacy compared with patients that disengaged. Patients with higher self-efficacy were more successful in

${ }^{4}$ Oxford Centre for Enablement, Oxford, UK

${ }^{5}$ Department of Rehabilitation Medicine, School for Public Health and Primary Care, Maastricht University, The Netherlands

\section{Corresponding author:}

Ingrid Brands, Department of Neurorehabilitation, Libra Rehabilitation Medicine and Audiology, Eindhoven, PO Box 1355, Eindhoven, 5602 BJ, The Netherlands.

Email: i.brands@libranet.nl 
attaining important life goals, which correlated with higher quality of life. Patients with higher self-efficacy, higher tenacity in goal pursuit, and higher flexibility in goal adjustment were less emotionally distressed, again correlating with higher quality of life.

Conclusions: To optimise adaptation it seems appropriate to promote self-efficacy and both tenacity and flexibility during rehabilitation treatment.

\section{Keywords}

Adaptation, self efficacy, goals, quality of life, brain injury, coping skills

Received: 29 July 20I3; accepted: 3 August 2014

\section{Introduction}

Acquired brain injury (ABI) causes impairments in various domains of functioning, which often remain indefinitely. ${ }^{1}$ The adaptation process after acquired brain injury is theoretically characterised by finding a balance between achieving maximal restoration of function and adjusting to various long-term limitations. ${ }^{2}$ An important aspect in this process of adaptation is building a new perspective about life, altering expectations about the future and rebuilding or restoring one's self-concept and/ or self-image. ${ }^{2}$ Gracey et al. ${ }^{3}$ describe this process as the reduction of the social, interpersonal and personal discrepancies between the experienced self post-injury and the pre-injury or aspired self. Negative changes in self-concept content are associated with lower well-being and increased psychosocial burden..$^{4,5}$

Reformulation of goals is an essential part in the reduction of self-discrepancies. ${ }^{3}$ Goals are central to some influential theories developed to explain human behaviour. ${ }^{6-8}$ In line with these theories, we formulated the process of adaptation in terms of discrepancy reduction between one's life goals and one's actual performance. ${ }^{2}$ Based on accomplishments and failures experienced in managing one's day-to-day problems associated with acquired brain injury, one learns if one's long-term higher order life goals are attainable. ${ }^{2}$ So, a continuous process of evaluation takes place in which the size of the goal-performance discrepancy is a major determinant of goal revision. Furthermore, the experienced rate of progress towards one's goals is compared to an expected rate of progress, which engenders positive or negative emotions. ${ }^{6}$ Increased well-being has been associated with successful pursuit of meaningful and attainable goals in patients with acquired brain injury. ${ }^{9}$ Negative emotions arise when goal attainment is unsatisfactory. This can lead to increased efforts to catch up but also to frustration when anticipated goals appear to be unreachable. ${ }^{6}$ Thus, finding the proper balance between tenacious goal pursuit and flexible goal adjustment ${ }^{8}$ is crucial in gaining emotional stability and preventing striving towards the unattainable, ending up in frustration. ${ }^{2}$ For example, emotional well-being and quality of life was highest in individuals showed high levels of both tenacity and flexibility. ${ }^{10,11}$

Self-efficacy refers to the belief in one's capabilities in achieving goals. ${ }^{12}$ Efficacy beliefs influence the activities people choose to engage in, the level of effort they spend and their perseverance in the face of difficulties. ${ }^{12}$ In the healthy population, individuals with a low level of self-efficacy disengage at an earlier level of task difficulty compared with highly self-efficacious individuals. ${ }^{13}$ Higher self-efficacy has been associated with better quality of life and social participation in patients with traumatic brain injury. ${ }^{14-17}$

The aim of the present study was to test if life goal attainment is related to adaptation after acquired brain injury, as this is the central assumption in our theoretical model, ${ }^{2}$ and to explore the role of self-efficacy and tenacity and flexibility in goal pursuit on adaptation. First we examined (1) success in attainment of important life goals and 
satisfaction with attainment; (2) how patients adjusted life goals if unattained, and (3) whether type of goal adjustment was dependent on level of goal attainment and satisfaction, self-efficacy, tenacity in goal pursuit and flexibility in goal adjustment. Second, we examined whether self-efficacy for managing brain injury-specific symptoms, tenacity and flexibility and long-term goal attainment contributed to good adaptation by affecting levels of emotional distress and quality of life. We hypothesized that one year post-discharge home (1) the majority of patients do not adapt their important unattained life goals, (2) in patients with higher self-efficacy, goal attainment is more successful, less emotional stress is perceived and quality of life is better, and (3) in patients with higher flexibility and tenacity adaptation is more successful.

\section{Methods}

\section{Patients}

Between January 2011 and January 2012, rehabilitation physicians and neurologists of the participating institutes (two rehabilitation centres and two hospitals in the South of the Netherlands) recruited patients who were eligible for participation in this prospective clinical cohort study. Patients were included consecutively upon return to the home environment, either at the start of outpatient neurorehabilitation or at discharge home from hospital or inpatient neurorehabilitation.

The inclusion criteria were: (1) age $\geq 18$ years; (2) newly acquired, non-progressive brain injury of any aetiology confirmed by neurological and/or neuroimaging data with impairments and disabilities in at least one domain of functioning at the time of inclusion, likely to persist for at least a few months; (3) for patients recruited at the start of an outpatient rehabilitation programme maximum time since injury was four months.

Exclusion criteria were: (1) any premorbid progressive brain disease; (2) insufficient command of the Dutch language; (3) inability to complete questionnaires based on clinical judgement (aphasia, severe cognitive impairment).

This study was approved by the medical ethics committees of Maastricht University Medical Centre and all participating hospitals and rehabilitation centres. All patients provided written informed consent.

\section{Measures}

To measure self-efficacy for managing brain injury-specific symptoms, we used the 13-item TBI Self-efficacy Questionnaire (SEsx), ${ }^{14}$ which contains four subscales: social (4 items), physical (1 item), cognitive (4 items) and emotional (4 items) measuring self-efficacy for obtaining help and emotional support, managing physical symptoms, managing and compensating for cognitive symptoms, and managing emotional symptoms respectively. Items scores $(1=$ not at all confident, to $10=$ totally confident) are summed per subscale. Subscale scores are summed to a total score (range 10 to 130). Higher scores indicate greater self-efficacy. We carried out a formal translation procedure to obtain a Dutch version. Using our data, we found good internal reliability (Cronbach's $\alpha .81$ to .95 ).

To measure tenacity in goal pursuit and flexibility in goal adjustment, we used the Assimilative/ Accommodative Coping Questionnaire (AACQ). ${ }^{8}$, ${ }^{18}$ We used the Dutch translation ${ }^{18}$ of the original German version of the questionnaire. ${ }^{8}$ The tenacity scale (Tenacious Goal Pursuit, TGP) measures the tendency to maintain a chosen course of action, to persist in goal pursuit even in the face of setbacks and obstacles. The flexibility scale (Flexible Goal Adjustment, FGA) measures the tendency to adjust to situational constraints and describes processes related to disengagement from blocked goals, reorientation, and acceptance. Each scale consists of 15 direct- and reverse-keyed answers rated on a 5 -point scale $(0=$ completely agree to $4=$ completely disagree). Higher scores indicate a greater tendency towards tenacity or flexibility. Using our data, we found good internal reliability (Cronbach's $\alpha:$ TGP $=.81$, FGA $=.79$ ).

The Hospital Anxiety and Depression Scale (HADS) was used as a general measure of emotional distress. The HADS contains 14 items, scored on a 4-point scale (range, 0 to 3 ) that form two subscales: anxiety and depression ( 7 items per subscale). ${ }^{19}$ HADS subscale scores $\geq 8$ might 
indicate the presence of depression or anxiety. A Dutch version was validated by Spinhoven et al. ${ }^{20}$ Using our data, we found good internal reliability (Cronbach's $\alpha$ : HADS-anxiety $=.85$, HADSdepression $=.84$ ).

The 9-item Life Satisfaction Questionnaire (LiSat-9) was used as a generic instrument for measuring quality of life. ${ }^{21}$ We used the Dutch version. ${ }^{22,23}$ One global domain (general quality of life) and eight specific fields are assessed. The mean of all item scores $(1=$ very unsatisfactory, to $6=$ very satisfactory) is calculated. Higher scores indicate better general quality of life. Using our data, we found good internal reliability (Cronbach's $\alpha .83$ ).

Attainment of life goals and satisfaction with goal attainment was rated on a 10 -point scale $(0=$ completely not reached to $10=$ completely reached and $0=$ completely unsatisfied to $10=$ completely satisfied respectively). The way in which patients adjusted their life goals in case of a goal attainment score $<10$ was classified into four categories: (1) maintained original goal (maintain), (2) made original goal easier as to a level that was judged attainable (easier), (3) stopped striving towards original goal as current level of attainment was accepted as sufficient (accept), (4) abandoned original goal (abandon).

Data on age, sex and diagnosis were extracted from the medical files. Level of educational attainment was recorded during baseline interview and classified according to a 3-level system often used in the Netherlands: primary education (low), junior vocational training (medium) and senior vocational or academic training (high), corresponding to $8.6 \pm$ $1.9,11.4 \pm 2.5$, and $15.2 \pm 3.3$ years of full-time education, respectively. ${ }^{24}$

\section{Procedure}

After inclusion, patients were contacted. A telephone interview with the first author or research assistant was planned when the patient had been at home for at least 2-4 weeks. During the telephone interview, patients were asked what were their three most important, most valuable life goals, based on their current situation to achieve in about a year. Goals were specified and made measurable but were not reviewed clinically to measure likelihood of achievement; for example goals such as 'I want to return to my prior work for 20 hours per week and do my original tasks with no adaptations in difficulty and complexity' or 'I want to be a member of my athletics club again and run once a week $10 \mathrm{~km}$ at low speed (beginners level instead of advanced level)' might have been judged by the assessor as impossible, but they were still recorded. After the interview, each patient received the questionnaires about self-efficacy (SEsx), tenacity/flexibility (AACQ), emotional distress (HADS) and quality of life (LiSat-9) by post to complete via self-report.

One year ( \pm 4 weeks) after inclusion patients were contacted again to plan the follow-up telephone interview. During this telephone interview attainment of the patient's initial life goals was reviewed. Each of three initial goals was read to the patient and he/she was asked to describe the actual level of achievement in detail. For each initial goal the investigator, in accordance with the patient, rated to what extent the goal was attained (from 0 to 10), next the patient rated how satisfied he/she was with the actual level of achievement (from 0 to $10)$. If the initial goal was not reached (score $<10$ ) patients were asked to indicate in what way they adjusted their initial goal: four answering categories were presented, (maintain, easier, accept, abandon) of which one had to be selected. After the interview, the same set of questionnaires about self-efficacy, tenacity/flexibility, emotional distress and quality of life was sent to complete via self-report.

If during the telephone interview a participant requested a live interview or asked for assistance to complete the questionnaires, a face-to-face appointment with the first author or research assistant was arranged $(n=26,18 \%$ of cases at baseline; $n=26$, $18 \%$ of cases at follow-up).

\section{Data analysis}

Paired sample $t$-tests were used to compare baseline and follow-up scores of all clinical variables.

Differences in self-efficacy (SEsx), flexibility (FGA) and tenacity (TGP), life goal attainment and 
satisfaction with attainment according to the type of goal adjustment (maintain, easier, accept, abandon) were tested using random effects regression analysis. This approach was chosen in order not to restrict analysis to a particular life goal, and hence accounted for the fact that repeated measures were taken from individuals when asking patients to define three different life goals. Thus, analyses made full use of all available data but they were adjusted for the fact that repeated measures are correlated within individuals, yielding pooled effect estimates. Five random effects regressions were conducted with SEsx, FGA, TGP, life goal attainment and satisfaction scores as dependent variables, respectively. Demographic variables (age, sex and education) and goal adjustment were entered as independent variables.

To test which clinical variables (SEsx, FGA, TGP, 3 goal attainment scores) contributed to successful adaptation as measured in terms of emotional distress (HADS) and quality of life (LiSat-9) at one-year follow-up, structural equation modelling (SEM) was performed. Both direct and indirect pathways were specified to test for possible effect mediation. To reduce the number of variables, a single 'goal attainment' score was constructed by factorizing the three separate goal attainment scores into a single continuous factor using a maximum likelihood estimator. An initial model was specified based on our theoretical assumptions on the direct and indirect paths between variables to influence HADS and LiSat-9 scores. The initial model was re-specified based on consecutive removal of paths that did not contribute significantly $(P \leq .10)$. This was executed in a 1-to-1 backward fashion. Model fit was assessed after each step by inspecting the model chi-square $\left(\chi^{2}{ }_{M}\right)$ next to the root mean square error of approximation (RMSEA) and the Comparative Fit Index (CFI). For the RMSEA ${ }^{25}$, scores $\leq 0.08$ indicate acceptable fit, and scores $\leq 0.05$ indicate good fit. The $\mathrm{CFI}^{26}$ ranges from 0 to 1 with scores $\geq 0.90$ indicating acceptable fit, and scores $\geq 0.95$ indicating good fit.

All analyses were carried out in Stata 12.1 (StataCorp LP, Texas), using two-sided hypothesis testing with an alpha-level of .05.

\section{Results}

Initially, 190 patients were approached, 37 refused to participate. Of the 153 patients willing to participate, we excluded 5 patients because of non-matching inclusion criteria. Overall, 148 patients (78\%) underwent baseline assessment, of which 143 participated in follow-up assessment. Too much burden was the reason for all dropouts. Table 1 shows the demographic and injury-related characteristics of the sample at baseline. At follow-up, mean time since injury was 67 weeks $(S D=9.12)$. Description of all clinical variables is summarized in Table 2. HADS-D scores were above cut-off indicative for depression in $37 \%$ of patients at baseline and in $32 \%$ at follow-up. For HADS-A, $32 \%$ of patients scored above the cut-off for anxiety at both measurements. Compared with baseline scores, average HADS and SEsx scores had improved at one-year follow-up (Table 2).

\section{Life goal attainment at one-year follow-up}

In total 426 goals were evaluated at follow-up. At one-year follow-up, full goal attainment was reached in $13 \%$ of initial goals. From the unattained initial life goals (score $\leq 9$ ), $58 \%$ were maintained as originally formulated, $31 \%$ were no longer striven for as the current level of attainment was accepted as sufficient, $9 \%$ were made easier so as to bring aspirations to a realistic level, $2 \%$ were abandoned. In Table 3, mean SEsx, FGA and TGP scores are given according to level of goal attainment and type of goal adjustment.

Separate linear random effect regressions were then run to investigate whether SEsx scores, TGP and FGA scores and attainment and satisfaction scores differed according to the type of goal adjustment in patients which did not attain their original life goals. There were no significant differences in SEsx scores and FGA scores across types of goal adjustment. Yet, compared with patients who maintained striving towards their original unmet goal, those who accepted their actual level of goal attainment and stopped striving showed significantly lower TGP scores $(b=-1.31,95 \% \mathrm{CI}-2.38$ to $-0.25, P=.016)$. In addition, those who abandoned their original goal were less successful in actual level of goal attainment $(b=-3.97,95 \%$ CI -5.62 
Table I. Patient characteristics at baseline $(n=\mid 48)$.

\begin{tabular}{lllll}
\hline & & Mean & SD & Range \\
\hline Age (years) & & 56 & 12.3 & $19-84$ \\
Time since injury (weeks) & & 15.1 & 9.6 & $2.0-43.7$ \\
Sex (male) & & $n$ & $\%$ & \\
Educational level & Low & 95 & 64.2 & \\
& Medium & 41 & 27.7 & \\
Type of lesion & High & 61 & 41.2 & \\
& Infarction & 46 & 31.1 & \\
& SAH & 98 & 66.2 & \\
& ICH & 10 & 6.8 & \\
& Diffuse vascular lesions & 9 & 6.1 & \\
& TBI & 2 & 1.4 & \\
& Anoxic encephalopathy & 14 & 9.5 & \\
& Tumour benign & 3 & 2.0 & \\
& Meningitis/encephalitis & 5 & 3.4 & \\
& Other & 1 & 0.7 & \\
\hline
\end{tabular}

SAH, subarachnoid haemorrhage; ICH, intracerebral haemorrhage; $\mathrm{TBI}$, traumatic brain injury.

Table 2. Descriptive data of all clinical variables.

\begin{tabular}{|c|c|c|c|c|c|c|}
\hline & \multicolumn{2}{|c|}{ Baseline } & \multicolumn{2}{|c|}{ I-year follow-up } & \multirow[t]{2}{*}{$t$} & \multirow[t]{2}{*}{$P$} \\
\hline & Mean & $\mathrm{SD}$ & Mean & SD & & \\
\hline SEsx & 83.98 & 22.37 & 87.40 & 21.29 & 2.14 & .03 \\
\hline FGA & 36.85 & 8.59 & 38.13 & 8.54 & 1.92 & .06 \\
\hline TGP & 35.35 & 9.46 & 34.22 & 8.83 & -1.45 & .15 \\
\hline HADS & 11.87 & 7.34 & 10.76 & 7.70 & -2.19 & .03 \\
\hline LiSat-9 & 4.49 & 0.73 & 4.54 & 0.85 & 0.85 & .39 \\
\hline
\end{tabular}

SEsx, TBI Self-efficacy Questionnaire; FGA, Flexible Goal Adjustment; TGP, Tenacious Goal Pursuit; HADS, Hospital Anxiety and Depression Scale; LiSat-9, Life Satisfaction Questionnaire.

to $-2.33, P \leq .001)$ and less satisfied with their goal attainment $(\mathrm{b}=-1.27,95 \% \mathrm{CI}-2.55$ to -0.002 , $P=.050)$ compared with those who maintained striving towards their unmet original goals.

\section{Adaptation at one-year post-discharge home: effect of self-efficacy, tenacity and flexibility and goal attainment on emotional distress and quality of life}

Structural equation modelling (SEM) was used to test for direct and indirect effects of SEsx, TGP and
FGA on goal attainment and adaptation outcome variables at follow-up. The initial theoretical model is shown in Figure 1. Model fit was high $\left(\chi^{2}{ }_{M}=\right.$ 9.61 with 10 degrees of freedom, RMSEA $=0.00$, $\mathrm{CFI}=1.00$ ), which is explained by the close fit for the measurement part of the SEM that generates the goal attainment factor (for an explanation see supplementary material Appendix).

Finally, a more parsimonious, reduced model (Figure 2) was obtained after consecutive backward removal of non-significant paths $\left(\chi_{\mathrm{M}}^{2}=11.43\right.$ with 15 degrees of freedom, $\mathrm{RMSEA}=0.00, \mathrm{CFI}=$ 1.00). By combining the estimates of direct and indirect pathways in the final model, the total effect of each variable (SEsx, FGA, TGP, goal attainment and HADS) on LiSat-9 was calculated. Examination of direct, indirect and total effects suggested that higher LiSat-9 scores were directly dependent on lower HADS scores $(\beta=-0.45, P<.001)$, higher goal attainment factor $(\beta=0.35, P \leq .001)$, and higher FGA scores $(\beta=0.14, P=.048)$. While higher SEsx scores had no such direct effect, they had an indirect (i.e. mediated) effect on LiSat-9 scores via their association with higher goal attainment scores and lower HADS scores, thus explaining their significant total effect $(\beta=0.39, P<.001)$. Similarly, higher TGP scores did not show a direct 
Table 3. Self-efficacy, flexibility in goal adjustment and tenacity in goal pursuit as related to type of goal adjustment and level of goal attainment at one-year follow-up.

\begin{tabular}{|c|c|c|c|c|c|}
\hline \multirow{3}{*}{$\frac{\text { GAdj }}{G A}$} & \multirow{3}{*}{$\frac{\text { Full GA }}{\text { Mean (SD) }}$} & \multirow{3}{*}{$\begin{array}{l}\text { Maintain } \\
\text { Mean (SD) }\end{array}$} & Easier & \multirow{2}{*}{$\frac{\text { Accept }}{e \text { GA }}$} & \multirow[t]{2}{*}{ Abandon } \\
\hline & & & Incomplete GA & & \\
\hline & & & Mean (SD) & Mean (SD) & Mean (SD) \\
\hline GA & $10(0.00)$ & $5.79(2.50)$ & $6.36(1.60)$ & $5.88(2.95)$ & $1.86(2.61)$ \\
\hline Satisfaction & $9.17(1.00)$ & $6.04(2.25)$ & $6.64(1.64)$ & $6.79(1.94)$ & $4.43(2.44)$ \\
\hline SEsx & $99.44(19.30)$ & $86.88(21.08)$ & $85.42(21.77)$ & 83.91 (19.32) & $69.86(33.89)$ \\
\hline FGA & $39.78(8.08)$ & $37.61(8.74)$ & $38.36(11.42)$ & $38.34(6.98)$ & 33.71 (II.61) \\
\hline TGP & $36.70(9.10)$ & $35.13(8.99)$ & 33.79 (8.98) & 31.54 (7.62) & $33.29(I I .4 I)$ \\
\hline
\end{tabular}

GAdj, goal adjustment; GA, goal attainment.

Full GA: maximum score $(=10)$ on life goal attainment score. Incomplete GA: score 0-9 out of 10 on life goal attainment score. Types of goal adjustment: maintain, maintain original goal; easier, decrease difficulty of original goal; accept, accept actual level of goal attainment and stop striving; abandon, abandon original goal.

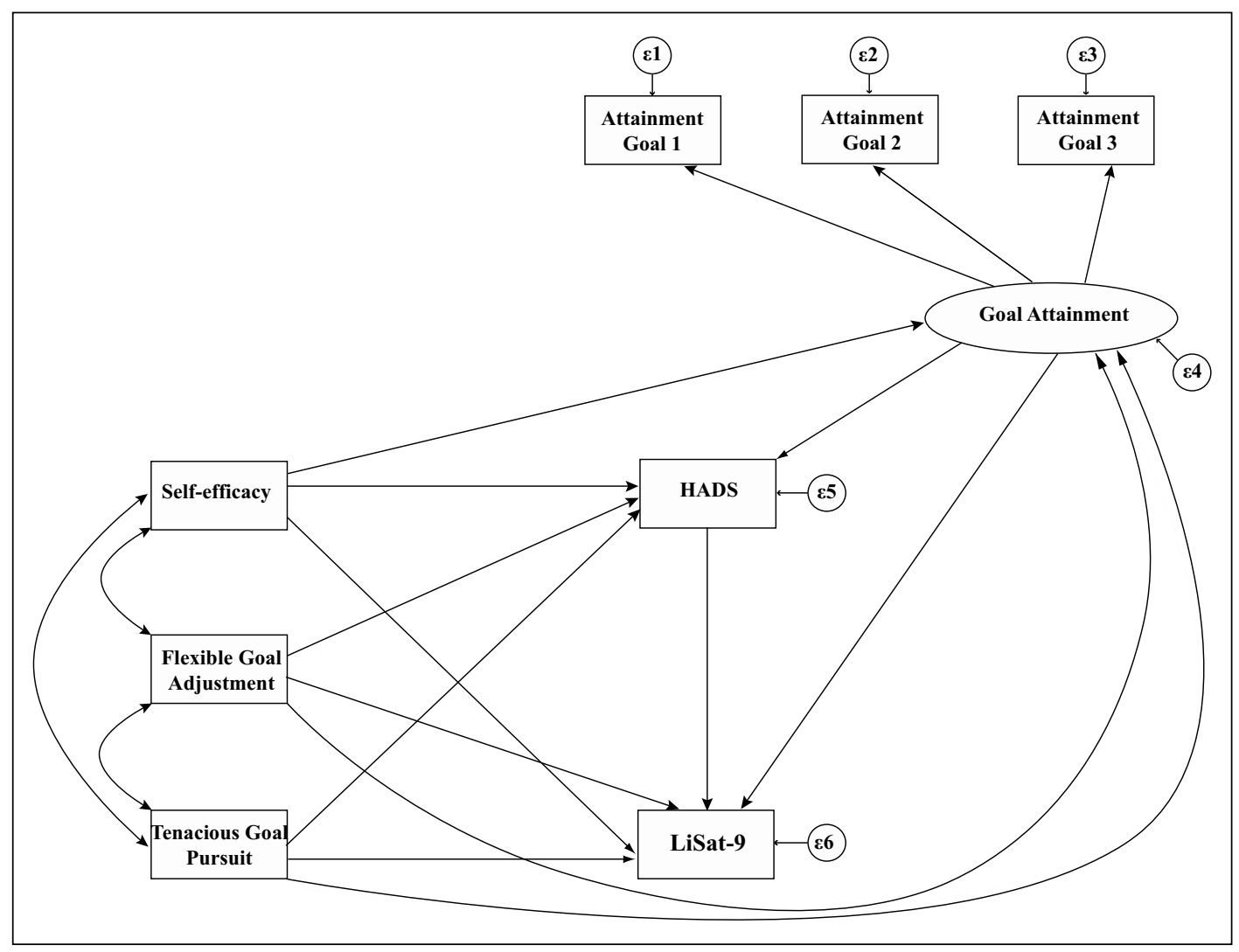

Figure I. Structural equation model of direct and indirect effects of self-efficacy, tenacity and flexibility and goal attainment on emotional distress and QoL: initial model.

HADS, Hospital Anxiety and Depression Scale; LiSat-9, Life Satisfaction Questionnaire; $\varepsilon$, error variance. 


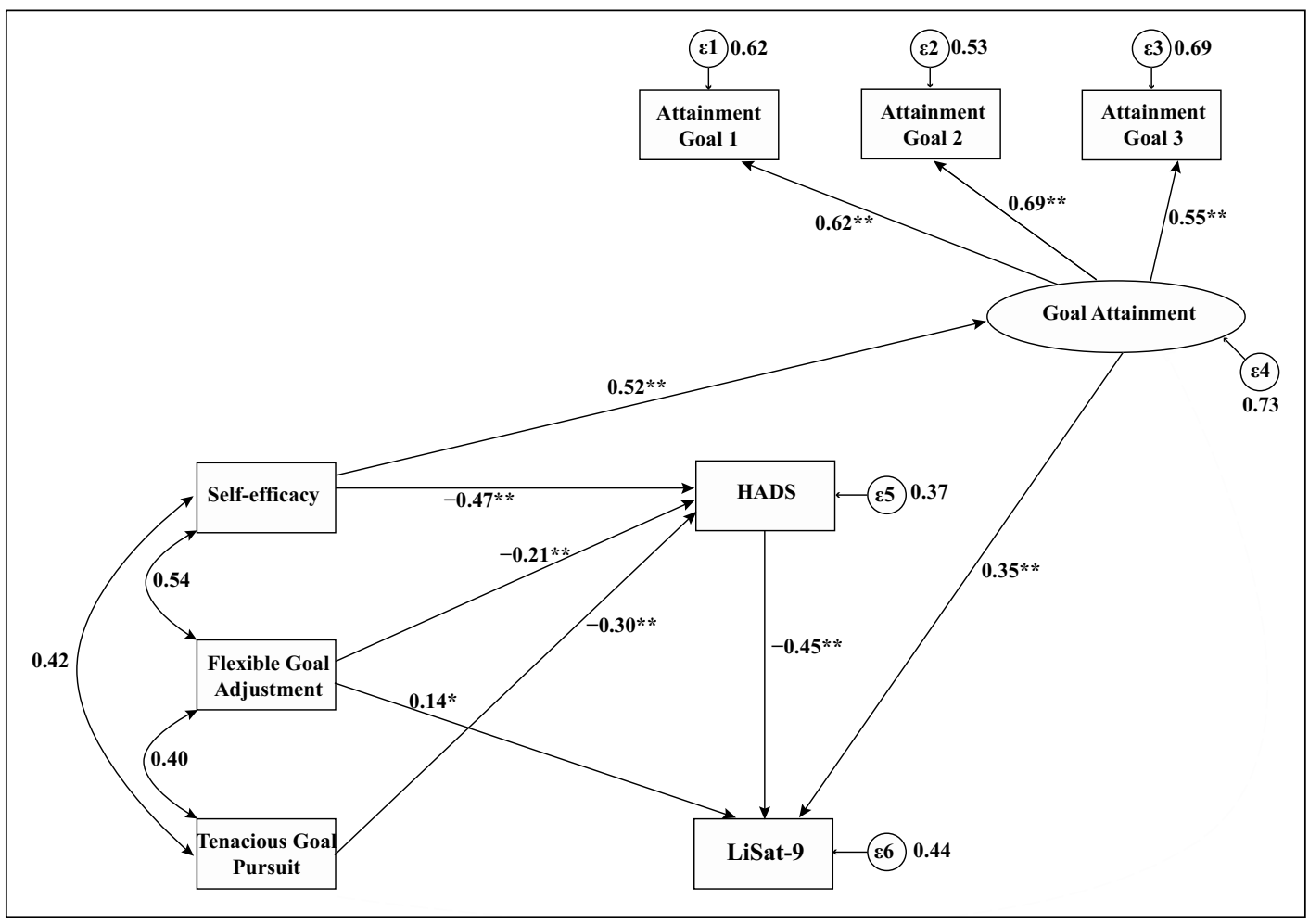

Figure 2. Structural equation model of direct and indirect effects of self-efficacy, tenacity and flexibility and goal attainment on emotional distress and QoL: final reduced model showing standardized regression coefficients for direct paths.

HADS, Hospital Anxiety and Depression Scale; LiSat-9, Life Satisfaction Questionnaire; $\varepsilon$, error variance. $* P<.05 ; * * P \leq .001$.

effect on LiSat-9, but a significant total effect $(\beta=$ $0.13, P<.001)$ because of their association with lower HADS scores. Next, higher FGA scores had both a direct effect on LiSat-9 scores $(\beta=0.14, P=$ $.048)$ and an indirect effect via lower HADS scores (total effect: $\beta=0.24, P=.001$ ). As no indirect paths were specified for goal attainment and HADS scores in the final model, their direct effects equalled their total effect.

For the adaptation outcome variables, $63 \%$ of the observed variance in HADS scores and $56 \%$ of the observed variance in LiSat-9 scores were explained by these associations.

\section{Discussion}

In this clinical study of patients with newly acquired brain injury, we found that only a minority of important life goals were completely met one year after discharge home. We showed that high self-efficacy for the management of brain injury-specific symptoms, high tenacity and flexibility in goal pursuit and successful attainment of important life goals were associated with better adaptation one year after discharge home.

When important life goals were not met one year post-discharge home, the majority of patients either continued striving towards their original goal, as we expected or accepted their current level of goal attainment as final, and stopped striving. Life goals appeared to be completely abandoned only if attainment was very low. Patients who continued striving towards their original life goals were more tenacious in goal pursuit than those who applied types of adjustment indicating partial disengagement. However, the patients who sustained 
effort did not have higher levels of self-efficacy although it is theoretically assumed that higher tenacity is associated with higher self-efficacy. ${ }^{27}$ Flexibility in goal pursuit was not linked to the way patients adjusted to unmet life goals.

At one year post-discharge home, patients who were more self-efficacious in managing their brain injury-related symptoms experienced less emotional distress and were more successful in attaining important life goals, which in turn correlated with better quality of life reflecting better adaptation. These findings are in line with the theory of Bandura in which higher self-efficacy is linked to better performance attainment. ${ }^{12}$ Self-efficacy also showed to be a reliable predictor of adjustment in patients with multiple sclerosis. ${ }^{28}$ The association between life goal attainment and higher quality of life mirrors earlier findings in brain injury. ${ }^{9}, 29,30$ The stress-buffering effect of self-efficacy is also well documented in healthy people ${ }^{31}$ and in patients with cancer. ${ }^{32,33}$

Better adaptation was also present in patients with higher tenacity in goal pursuit and higher flexibility in goal adjustment as they experienced lower emotional distress, which was again related to higher quality of life. Tenacity and flexibility did not play a role in goal attainment but being flexible in goal adjustment was directly related to better quality of life, independent of goal attainment per se. These findings are in line with the theoretical model that we proposed ${ }^{2}$ and with other models. ${ }^{6,27}$ Both assimilative and accommodative processes are activated by perceived goal-performance discrepancies, which is equivalent to the level of goal attainment in our model, in order to reduce these perceived discrepancies. ${ }^{27}$ Assimilative processes consist of corrective interventions that are initiated to maximize the likelihood of goal achievement. Accommodative processes constitute of rescaling ambitions and acceptance of the situation. ${ }^{27}$ Both processes also engender an emotional response. ${ }^{2,6}$, 27 The adaptation process after acquired brain injury is presumably characterised by finding a balance between achieving maximal restoration of function and adjusting to various long-term limitations. ${ }^{2}$ Our findings indicate that at one-year post-injury both assimilative and accommodative processes are into play simultaneously and seem to act complementarily and synergistically to create emotional stability. ${ }^{2}$ Similar to our findings, in patients with stroke one-year post-onset, quality of life was found highest in the presence of high levels of both tenacity and flexibility. ${ }^{11}$ Also in patients with a lower limb amputation (mean time since amputation $=32$ weeks), better quality of life was associated with higher tenacity and flexibility. ${ }^{34}$ However, better acceptance was only related to higher flexibility in goal adjustment in patients with spinal cord injury in the chronic stage (mean time since injury $=8.5$ years), ${ }^{35}$ suggesting that, possibly, with ongoing time the tendency towards flexibility might become more important.

Self-efficacy for managing brain injury-related symptoms was moderately correlated with both tenacity and flexibility. This corresponds to our theoretical assumptions ${ }^{2}$ that both assimilative and accommodative tendencies represent different means to exert self-control.

Our findings suggest that therapeutic attempts to enhance self-efficacy related to the management of brain injury-specific symptoms, as well as interventions to increase tenacity in goal pursuit and flexibility in goal adjustment would be useful in improving attainment of important life goals and adaptation after acquired brain injury.

Self-efficacy does change, as we found an improvement over the course of a year, and thus interventions could well increase this potentially beneficial change. Indeed, after acquired brain injury cognitive behavioural therapy, mindfulnessbased training or individualised self-management workbooks have all been successful in increasing domain-specific self-efficacy. ${ }^{36-38}$ According to Bandura, ${ }^{12}$ self-efficacy beliefs are, in addition to training skills and strategies, developed by using referential comparison with significant others, positive feedback, reward and providing control over interfering emotions e.g. stress, anxiety and fatigue.

Although tenacity and flexibility are predominantly viewed as dispositional characteristics, fluctuations over the course of a lifetime were observed, which suggests that they can also be changed. ${ }^{8}$ Stimulating assimilative as well as accommodative tendencies are central to holistic rehabilitation 
approaches aiming at optimizing the process of adaptation after acquired brain injury. ${ }^{3}$ Various therapeutic techniques e.g. behavioural experiments and motivational interviewing are used to support patients in self-reflection, selecting logical sub-goals, environmental mastery and recruiting resources, exploring alternative perspectives and reducing catastrophizing thoughts. ${ }^{3,39-41}$

It is well known that rehabilitation after acquired brain injury is more successful and motivation increases when personally important goals are set, which are concurrent with one's life goals. ${ }^{42-44}$ Our findings stress the importance of such an approach, as we showed that attainment of important life goals is associated with better long-term quality of life. We did not constrain goals by achievability, and interestingly the patients rarely considered that they had a major lack of achievement. Some modification of initial goals might be appropriate, but major attempts to alter patient-set goals in the early stage after brain injury, might carry the risk of demotivating the patient.

We did not formally account for type of injury, injury severity or lesion location. However, exploratory analyses did not show any influence. Our choice not to limit inclusion criteria for this study to one specific diagnosis was to increase generalizability and validity. Our results cannot be extrapolated to the whole acquired brain injury population as we did not include people who required long-term residential care but we think our study sample is representative of the acquired brain injury population that is discharged home. We did not include brain injury-related characteristics such as self-awareness and cognitive functioning in our analyses, nor did we account for classical coping styles although they are assumed of influence. ${ }^{2,3}$ Therefore our findings must be interpreted as a first exploration and testing of the relationships between a set of variables, that are presumed to be involved in the adaptation process after acquired brain injury. ${ }^{2}$ As a consequence of testing our model at only one point in time (at one-year follow-up), estimation of reciprocal effects (e.g. a pathway from HADS towards SEsx or from goal attainment towards SEsx) was not possible. ${ }^{45}$

\section{Conclusions}

In patients with acquired brain injury, one year after discharge home, the majority of important life goals is not met and striving for continued. Compared with patients that apply types of goal adjustment pointing towards disengagement, patients who sustain effort to reach their initial life goals, have higher tenacity but do not differ in level of self-efficacy. Furthermore, we showed that high self-efficacy for the management of brain injuryspecific symptoms, high tenacity in goal pursuit, high flexibility in goal adjustment and successful attainment of important life goals is associated with better adaptation after acquired brain injury. For clinical practice, we stress the importance of promoting self-efficacy and both assimilative and accommodative qualities during rehabilitation treatment.

\section{Clinical messages}

- One year after acquired brain injury, only a minority of important life goals are completely met.

- Life goals are completely abandoned, only if attainment is very low.

- Patients with high self-efficacy are more successful in attainment of life goals.

- Major modification of initial goals might demotivate the patient.

\section{Conflict of interest}

The authors declare no conflict of interest.

\section{Funding}

This research was in part financially supported by $\mathrm{CZ}$ Fonds Grant AFVV11-045.

\section{References}

1. Dikmen SS, Machamer JE, Powell JM and Temkin NR. Outcome 3 to 5 years after moderate to severe traumatic brain injury. Arch Phys Med Rehabil 2003; 84: 1449-1457.

2. Brands IM, Wade DT, Stapert SZ and van Heugten CM. The adaptation process following acute onset disability: an interactive two-dimensional approach applied to acquired brain injury. Clin Rehabil 2012; 26: 840-852. 
3. Gracey F, Evans JJ and Malley D. Capturing process and outcome in complex rehabilitation interventions: A "Y-shaped" model. Neuropsychol Rehabil 2009; 19: 867-890.

4. Cantor JB, Ashman TA, Schwartz ME, et al. The role of self-discrepancy theory in understanding post-traumatic brain injury affective disorders: a pilot study. $J$ Head Trauma Rehabil 2005; 20: 527-543.

5. Doering BK, Conrad N, Rief W and Exner C. Living with acquired brain injury: Self-concept as mediating variable in the adjustment process. Neuropsychol Rehabil 2011; 21: 42-63.

6. Carver CS and Scheier MF. On the self-regulation of behaviour. Cambridge: Cambridge University Press, 1998.

7. Bandura A. Social Foundations of Thought and Action. Englewood Cliffs, NJ: Prentice-Hall, 1986.

8. Brandtstadter $\mathrm{J}$ and Renner G. Tenacious goal pursuit and flexible goal adjustment: Explication and age-related analysis of assimilative and accommodative strategies of coping. Psychol Aging 1990; 5: 58-67.

9. Conrad N, Doering BK, Rief W and Exner C. Looking beyond the importance of life goals. The personal goal model of subjective well-being in neuropsychological rehabilitation. Clin Rehabil 2010; 24: 431-443.

10. Kelly RE, Wood AM and Mansell W. Flexible and tenacious goal pursuit lead to improving well-being in an aging population: a ten-year cohort study. Int Psychogeriatr 2013; 25: 16-24.

11. Darlington A-SE, Dippel DWJ, Ribbers GM, van Balen $\mathrm{R}$, Passchier J and Busschbach JJV. Coping strategies as determinants of quality of life in stroke patients: a longitudinal study. Cerebrovasc Dis 2007; 23: 401-407.

12. Bandura A. Self-efficacy : the exercise of control. New york: W.H. Freeman and Company, 1997.

13. Beattie $\mathrm{S}$ and Davies M. A test of engagement versus disengagement in catastrophe models. Br J Psychol 2010; 101: 361-371.

14. Cicerone KD and Azulay J. Perceived self-efficacy and life satisfaction after traumatic brain injury. $J$ Head Trauma Rehabil 2007; 22: 257-266.

15. Rutterford NA and Wood RL. Evaluating a theory of stress and adjustment when predicting long-term psychosocial outcome after brain injury. J Int Neuropsychol Soc 2006; 12: 359-367.

16. Wood RL and Rutterford NA. Demographic and cognitive predictors of long-term psychosocial outcome following traumatic brain injury. J Int Neuropsychol Soc 2006; 12: 350-358.

17. Dumont C, Gervais M, Fougeyrollas P and Bertrand R. Toward an explanatory model of social participation for adults with traumatic brain injury. $J$ Head Trauma Rehabil 2004; 19: 431-444.

18. Aben L and Busschbach JJ. A formal translation of the Assimilation-Accomodation Coping Scale from German to Dutch. Erasmus MC Report 2009.06.

19. Zigmond AS and Snaith RP. The hospital anxiety and depression scale. Acta Psychiatr Scand 1983; 67: 361-370.
20. Spinhoven P, Ormel J, Sloekers PPA, Kempen GIJM, Speckens AEM and Hemert AMV. A validation study of the Hospital Anxiety and Depression Scale (HADS) in different groups of Dutch subjects. Psychol Med 1997; 27: 363-370.

21. Fugl-Meyer AR, Branholm IB and Fugl-Meyer KS. Happiness and domain specific life satisfaction in adult northern Swedes. Clin Rehabil 1991; 5: 25-33.

22. Post MWM, de Witte LP, van Asbeck FWA, van Dijk AJ and Schrijvers AJP. Predictors of health status and life satisfaction in spinal cord injury. Arch Phys Med Rehabil 1998; 79: 395-401.

23. Visser-Meily A, Post M, Schepers V and Lindeman E. Spouses' quality of life 1 year after stroke: Prediction at the start of clinical rehabilitation. Cerebrovasc Dis 2005; 20: 443-448.

24. De Bie SE. Standaardvragen 1987: Voorstellen voor uniformering van vraagstellingen naar achtergrondkenmerken en interviews (Standard questions 1987: Proposal for uniformization of questions regarding background variables and interviews). Leiden: Leiden University Press, 1987.

25. Steiger JH. Structural model evaluation and modification: An interval estimation approach. Multivariate Behav Res 1990; 25: 173-180.

26. Bentler PM. Comparative fit indexes in structural models. Psychol Bull 1990; 107: 238-246.

27. Brandtstädter $\mathrm{J}$ and Rothermund $\mathrm{K}$. The life-course dynamics of goal pursuit and goal adjustment: a two-process framework. Dev Rev 2002; 22: 117-150.

28. Black R and Dorstyn D. A biopsychosocial model of resilience for multiple sclerosis. J Health Psychol. 2013 Published ahead of print 9 December 2013.

29. Doering BK, Nico C, Winfried R and Cornelia E. Life goals after brain injury in the light of the dual process approach: Empirical evidence and implications for neuropsychological rehabilitation. Neuropsychol Rehabil 2011; 21: 515-538.

30. Kuenemund A, Zwick S, Doering BK, Conrad N, Rief $\mathrm{W}$ and Exner C. Decline in attainability of communion and agency life goals over 2 years following acquired brain injury and the impact on subjective well-being. Neuropsychol Rehabil 2013; 23: 678-697.

31. Prati G, Pietrantoni L and Cicognani E. Self-efficacy moderates the relationship between stress appraisal and quality of life among rescue workers. Anxiety Stress Coping 2009; 23: 463-470.

32. Hirai K, Suzuki Y, Tsuneto S, Ikenaga M, Hosaka T and Kashiwagi T. A structural model of the relationships among self-efficacy, psychological adjustment, and physical condition in Japanese advanced cancer patients. Psychooncology 2002; 11: 221-229.

33. Deno M, Tashiro M, Miyashita M, et al. The mediating effects of social support and self-efficacy on the relationship between social distress and emotional distress in head and neck cancer outpatients with facial disfigurement. Psychooncology 2012; 21: 144-152. 
34. Coffey L, Gallagher P and Desmond D. Goal pursuit and goal adjustment as predictors of disability and quality of life among individuals with a lower limb amputation: a prospective study. Arch Phys Med Rehabil 2014; 95: 244-252.

35. van Lankveld $W$, van Diemen $T$ and van Nes I. Coping with spinal cord injury: tenacious goal pursuit and flexible goal adjustment. J Rehabil Med 2011; 43: 923-929.

36. Jones F, Mandy A and Partridge C. Changing self-efficacy in individuals following a first time stroke: preliminary study of a novel self-management intervention. Clin Rehabil 2009; 23: 522-533.

37. Azulay J, Smart CM, Mott T and Cicerone KD. A pilot study examining the effect of mindfulness-based stress reduction on symptoms of chronic mild traumatic brain injury/postconcussive syndrome. J Head Trauma Rehabil 2013; 28: 1117-1127.

38. Backhaus SL, Ibarra SL, Klyce D, Trexler LE and Malec JF. Brain injury coping skills group: a preventative intervention for patients with brain injury and their caregivers. Arch Phys Med Rehabil 2010; 91: 840-848.

39. Brands IMH, Bouwens SFM, Wolters Gregório G, Stapert SZ and van Heugten CM. Effectiveness of a process- oriented patient-tailored outpatient neuropsychological rehabilitation programme for patients in the chronic phase after ABI. Neuropsychol Rehabil 2013; 23: 202-215.

40. Cicerone KD, Mott T, Azulay J, et al. A randomized controlled trial of holistic neuropsychologic rehabilitation after traumatic brain injury. Arch Phys Med Rehabil 2008; 89: 2239-2249.

41. Prigatano GP. Principles of neuropsychological rehabilitation. New York: Oxford University Press, 1999.

42. Nair KPS. Life goals: the concept and its relevance to rehabilitation. Clin Rehabil 2003; 17: 192-202.

43. Nair KPS and Wade DT. Changes in life goals of people with neurological disabilities. Clin Rehabil 2003; 17: 797-803.

44. Bergquist TF, Micklewright JL, Yutsis M, Smigielski JS, Gehl C and Brown AW. Achievement of client-centred goals by persons with acquired brain injury in comprehensive day treatment is associated with improved functional outcomes. Brain Inj 2012; 26: 1307-1314.

45. Kline RB. Principles and practice of structural equation modeling. 3rd edition. New York: The Guilford Press, 2011. 